\title{
THE INTERACTION OF SILICIC ACID WITH IRON(III) AND URANYL IONS IN DILUTE AQUEOUS SOLUTION
}

\author{
RICHARD A. PORTER* and WALTER J. WEBER, Jr. \\ Department of Civil Engineering, The University of Michigan, Ann Arbor, Mich. 48104
}

(First received 2 October 1970 ; in revised form 20 November 1970 )

\begin{abstract}
The interaction of iron(III) and uranyl ions with dissolved silica is studied by a spectrophotometric technique. The interaction with iron is studied as a function of the degree of polymerization of the silica. For uranyl ion, a complex with monomeric silica is inferred. An equilibrium constant $\mathrm{p} Q_{1} \sim 2 \cdot 0$ for the equilibrium $\mathrm{UO}_{2}{ }^{2+}+\mathrm{Si}(\mathrm{OH})_{4}=\mathrm{UO}_{2} \mathrm{SiO}(\mathrm{OH})_{3}{ }^{1+}+\mathrm{H}^{+}$is measured.
\end{abstract}

\section{INTRODUCTION}

IN THE only previous quantitative study of complex formation between aqueous silicic acid and a metal ion, Weber and Stumm[1] found that the interaction with the iron(III) ion could be described by the equation

$$
\mathrm{Fe}^{3+}+\mathrm{Si}(\mathrm{OH})_{4}=\mathrm{FeSiO}(\mathrm{OH})_{3}{ }^{2+}+\mathrm{H}^{+}, Q_{1}
$$

An equilibrium constant $Q_{1}=0.57$ was obtained in $0.1 \mathrm{M} \mathrm{NaClO}_{4}$ media at $25^{\circ} \mathrm{C}$ by use of u.v. spectrophotometry. Attempts to reproduce this result in our laboratory, with the aim of extending the technique to other metal ions, have met with considerable difficulty. We will show here that much of the difficulty can be traced to the presence of multimeric silica species, assumed not to be present in the original work. Some data for the interaction of polymeric silica with iron(III) is given. Application of the spectrophotometric technique to the study of a silicato-uranyl complex is then presented.

\section{EXPERIMENTAL}

All chemicals used were reagent grade. Iron(III), uranyl, and sodium perchlorate were obtained from G. F. Smith and used without further treatment. A stock solution of $0.864 \mathrm{M} \mathrm{HClO}_{4}$ was used in all experiments. Measurements with iron used a common stock solution $8 \times 10^{-4} \mathrm{M}$ in $\mathrm{Fe}\left(\mathrm{ClO}_{4}\right)_{3}$ and $4.3 \times 10^{-2} \mathrm{M}$ in $\mathrm{HClO}_{4}$. The analysis for iron is based on the absorbance of a dilute acidified solution at $272 \mathrm{~m} \mu$ [2]. Measurements with uranium used a common stock solution $0 \cdot 106 \mathrm{M}$ in $\mathrm{UO}_{2}\left(\mathrm{ClO}_{4}\right)_{2}$ and $8.6 \times 10^{-3} \mathrm{M}$ in $\mathrm{HClO}_{4}$. The uranium analysis is based on the absorbance at $417 \mathrm{~m} \mu$ of an aliquot rendered 5 per cent in $\mathrm{HClO}_{4}$. A molar absorptivity $\epsilon=7 \cdot 1$ for uranyl ion in perchloric acid media can be inferred from literature data [3]. Baker and Adamson sodium silicate nonahydrate was used to prepare a $0.94 \mathrm{M}$ stock solution. This solution, somewhat turbid when first prepared, was filtered

*Present address: Department of Chemistry, University of Idaho, Moscow, Idaho 83843, U.S.A.

1. W. J. Weber, Jr. and W. Stumm, J. inorg. nucl. Chem. 27, 237 (1965).

2. H. Galal-Gorchev and W. Stumm, J. inorg. nucl. Chem. 25, 567 (1963).

3. L. Silverman and L. Moudy, Analyt. Chem. 28, 45 (1956). 
through a $0.45 \mathrm{~m} \mu$ Gelman filter and stored in a Nalgene polyethylene bottle. Analysis for silica was performed by the colorimetric silicomolybdate method [4].

For measurements with iron, five different stock solutions of silicic acid in various degrees of polymerization were prepared. The formal concentration of each solution was $1.9 \times 10^{-2} \mathrm{M}$ in terms of monomeric silica. Solution 1 was prepared by first mixing $20 \mathrm{ml}$ of $0.94 \mathrm{M} \mathrm{Na} \mathrm{SiO}_{3}$ with $100 \mathrm{ml}$ of $1 \mathrm{M} \mathrm{NaOH}$, then adding the mixture with rapid stirring to an excess of $\mathrm{HClO}_{4}$ which produced a final $\mathrm{pH} \sim 2$. Although the resulting solution is unstable with respect to polymerization [5], polymerization is quite slow at this $\mathrm{pH}[6]$. The mixture was then diluted to 11 . Solution 2 was prepared by direct neutralization of $0.94 \mathrm{M} \mathrm{Na} \mathrm{NaO}_{3}$ with excess $\mathrm{HClO}_{4}$, again to $\mathrm{pH} \sim 2$. Solutions $3-5$ were prepared by first doing a partial neutralization of $\mathrm{Na}_{2} \mathrm{SiO}_{3}$ with $\mathrm{HClO}_{4}$ to give a solution $3.8 \times 10^{-2} \mathrm{M}$ in silica and with $\mathrm{pH}$ 9-10. Under these conditions silicic acid polymerized to an appreciable extent over a period of several hours. A single solution was prepared in this way; aliquots were then drawn off at various times to be neutralized to $\mathrm{pH} \sim 2$ and diluted to a silica concentration of $1.9 \times 10^{-2} \mathrm{M}$.

For measurements with uranyl ion, varying amounts of $1 \mathrm{M} \mathrm{Na}_{2} \mathrm{SiO}_{3}$ were premixed with $1 \mathrm{M}$ $\mathrm{NaOH}$, then neutralized with $\mathrm{HClO}_{4}$ to $\mathrm{pH} \sim 3.5$. The stock solutions were $4.7-7.0 \times 10^{-2} \mathrm{M}$ in silica and were all $0 \cdot 4 \mathrm{M}$ in sodium ion. The acid and basic solutions were chilled before mixing to minimize the polymerization produced during mixing. The heat of neutralization raised the temperature to $\sim 20^{\circ} \mathrm{C}$ after mixing.

For a series of absorbance measurements, fixed aliquots of a silica stock solution and of the uranyl or iron stock solution were added to $100 \mathrm{ml}$ volumetric flasks. The $\mathrm{pH}$ was adjusted by adding varying amounts of $\mathrm{HClO}_{4}$, and the ionic strength was adjusted with a $\mathrm{NaClO}_{4}$ stock solution. The perchlorate ion concentrations were fixed at $0 \cdot 1 \mathrm{M}$ for the iron solutions and $0.2 \mathrm{M}$ for the uranium solutions. After dilution of $100 \mathrm{ml}$, the solutions were thermostatted in a $25^{\circ} \mathrm{C}$ temperature bath for 30 min before measurement of the absorbance.

Absorbance measurements were made with a Beckman Model DU spectrophotometer using 5 or $10 \mathrm{~cm}$ cells. The hydrogen ion concentrations were assessed for a given series with a fixed silica stock solution by measuring the $\mathrm{pH}$ of the least acid solution and calculating $\left[\mathrm{H}^{+}\right]$for the other solutions from the amount of perchloric acid added. $\mathrm{pH}$ measurements were made at $25^{\circ} \mathrm{C}$ with an Instrumentation Laboratories, Inc. model 205 pH meter and a combination glass-calomel electrode.

Some light scattering and differential refractometry experiments were carried out to estimate the molecular weight of polymerized silica solutions, and to study the effect of iron(III) ions on the rate of polymerization of silica under the conditions of our equilibrium experiments. A Brice-Phoenix Model 8P-2008-8 light scattering photometer and a Brice-Phoenix Model BP-2000-V differential refractometer were used for these measurements. A wavelength of $436 \mathrm{~m} \mu$ was used for both types of measurement. The weight-average molecular weight was estimated simply from the measured turbidity of the silica stock solutions; there was no correction for extrapolation to zero concentration. The weight fraction of silica is based on its weight as $\mathrm{SiO}_{2}$.

\section{Analysis of spectrophotometric data}

The interaction of the silanol groups of polymeric silica with $\mathrm{Fe}^{3+}$ can be written formally as

$$
(\rightarrow \mathrm{SiOH})_{m}+\mathrm{Fe}^{3+}=(\rightarrow \mathrm{SiOH})_{m-n}(\rightarrow \mathrm{SiO})_{n} \mathrm{Fe}^{(3-n)+}+n \mathrm{H}^{+}, Q_{n}
$$

The main point of this depiction of the equilibrium (which does not pretend to represent the true state of the polymeric silica) is to indicate the number of hydrogen ions released when ferric ion complexes with the silica. Equation (1) can be considered a special case in which $n=1$. On the other hand, ion exchange experiments of ferric ion with solid silica gel[7] can be interpreted by taking $n=3$. It would be expected that colloidal silicas should exhibit intermediate values of $n$. A similar range of behavior is expected for the acidity of the silanol groups. Monomeric silicic acid dissociates according to the equilibrium

4. Standard Methods for the Examination of Water and Wastewater p. 225. American Public Health Association, New York (1960).

5. W. Stumm, H. Huper and R. L. Champlin, Envir. Sci. \& Tech. 1, 221 (1967).

6. A. Audsley and J. Aveston, J. chem. Soc. 2320 (1962).

7. D. L. Dugger, J. H. Stanton, B. N. Irby, B. L. McConnell, W. W. Cummings and R. W. Maatman, J.phys. Chem. 68, 757 (1964). 


$$
\mathrm{Si}(\mathrm{OH})_{4}=\mathrm{SiO}(\mathrm{OH})_{3}{ }^{-}+\mathrm{H}^{+}
$$

for which [8] $\mathrm{p} K_{a}=9.5$. Estimates of the acidity of the silanol groups on silica gel $[7,9]$ give $\mathrm{p} K_{a} \sim 7$, indicating an increase of acidity with increasing polymerization.

Spectrophotometric measurements on the iron solutions were carried out at a wavelength of $272 \mathrm{~m} \mu$, the isobestic point for the equilibrium

$$
\mathrm{Fe}^{3+}+\mathrm{H}_{2} \mathrm{O}=\mathrm{FeOH}^{2+}+\mathrm{H}^{+}, * K_{1}
$$

For the conditions of our experiments $\left(\left[\mathrm{Fe}\left(\mathrm{ClO}_{4}\right)_{3}\right]=2 \cdot 4 \times 10^{-5}, \mathrm{pH}<2 \cdot 5\right)$, this is the only hydrolytic equilibrium that need be considered. By assuming Beer's law for the separate iron species, the following relation has been derived ( 1 ),

$$
\epsilon=\epsilon_{1}-\frac{\left(\epsilon-\epsilon_{0}\right)\left[\mathrm{H}^{+}\right]^{n-1}\left(\left[\mathrm{H}^{+}\right]+{ }^{*} K_{1}\right)}{Q_{n}[\mathrm{Si}]}
$$

where $\epsilon_{0}, \epsilon_{1}$, and $\epsilon$ are respectively the molar absorptivities (referred to the total iron concentration) of iron in the absence of silica, iron as a pure silicato complex, and the actual solution containing iron and silica. [Si] represents the total of all silica species. $\epsilon_{0}$ is a constant for the iron experiments. To determine the value of $n$, it is convenient to cast Equation (5) in logarithmic form to give

$$
-\log _{10}\left\{\frac{\left(\epsilon-\epsilon_{0}\right)\left(\left[\mathrm{H}^{+}\right]+* K_{1}\right)}{\epsilon_{1}-\epsilon}\right\}=(n-1) \mathrm{pH}-\log _{10}\left\{Q_{n}[\mathrm{Si}]\right\}
$$

This relation contains three parameters: $n, \epsilon_{1}$, and the product $Q_{n}[\mathrm{Si}]$. This method of parameterization of the data for polymeric silica is doubtless not unique, but turns out to be useful and instructive.

The experiments with uranyl ion were conducted with $\mathrm{pH} \sim 3.7$ and $\left[\mathrm{UO}_{2}\left(\mathrm{ClO}_{4}\right)_{2}\right]=6.4 \times 10^{-4}$. Under these conditions the dimerization equilibrium

$$
2 \mathrm{UO}_{2}{ }^{2+}+2 \mathrm{H}_{2} \mathrm{O}=\left(\mathrm{UO}_{2}\right)_{2}(\mathrm{OH})_{2}{ }^{2+}+2 \mathrm{H}^{+},{ }^{*} \beta_{2,2}
$$

must be considered as well as the analogue to Equation (4). An analysis similar to that which led to Equation (5) may be carried out, leading to the relation

$$
\epsilon=\epsilon_{1}-\frac{\left(\epsilon-\epsilon_{0}\right)\left[\mathrm{H}^{+}\right]^{n-1}\left(\left[\mathrm{H}^{+}\right]+{ }^{*} K_{1}+{ }^{*} \beta_{2,2}\left[\mathrm{UO}_{2}{ }^{2+}\right] /\left[\mathrm{H}^{+}\right]\right)}{Q_{n}[\mathrm{Si}]}
$$

The term $\epsilon_{0}$, the molar absorptivity in the absence of silica, is now not a constant but must be determined as a function of $\mathrm{pH}$ for a fixed wavelength and uranium concentration. Since the concentration of hydrolytic species is $\sim 1$ per cent or less for our conditions, we can approximate $\left[\mathrm{UO}_{2}{ }^{2+}\right] \approx$ total uranium concentration for the small term in which it appears. We have not attempted to assess complexation with the dimeric uranium species.

\section{RESULTS AND DISCUSSION}

Iron. The data for iron solutions prepared with silica stock solutions 1-3 and 5 is plotted in Fig. 1 according to Equation (5) with $n=1$. The data for solution 4 is omitted to save confusion; it is intermediate to solutions 3 and 5: [Si] is taken to be constant. A value ${ }^{*} K_{1}=2 \cdot 89 \times 10^{-3}$ was used[10]. The equation gives a linear fit with negative slope only for solution 1 . For the other solutions we apparently have $n>1$.

8. H. Bilinski and J. Ingri, Acta chem. scand. 21, 2503 (1967).

9. I. Altug and M. L. Hair, J. phys. Chem. 71, 4260 (1967).

10. R. M. Milburn, J.Am. chem. Soc. 79, 537 (1957). 


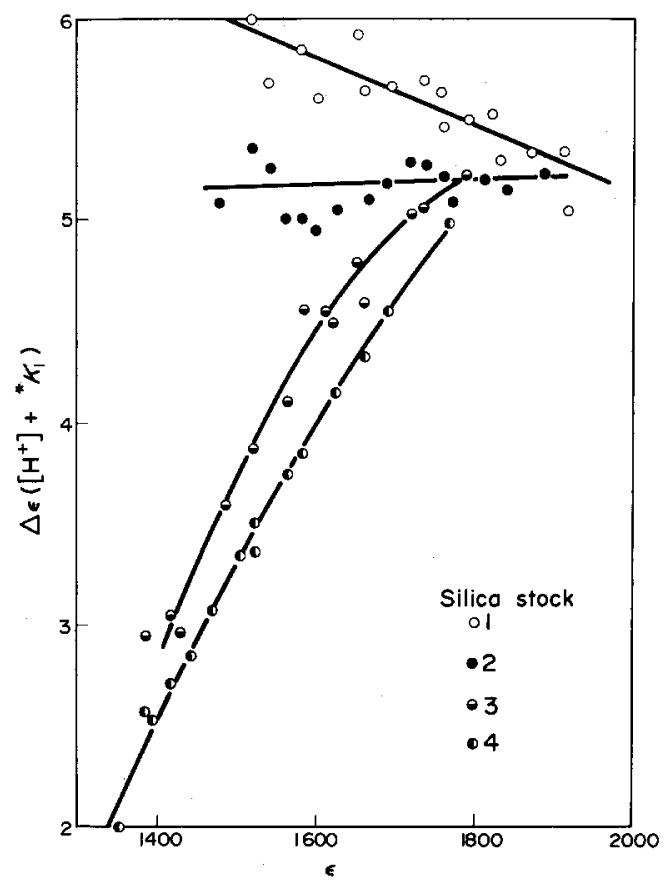

Fig. 1. Analysis of iron(III)-silica interaction according to Equation(5) with $n=1$.

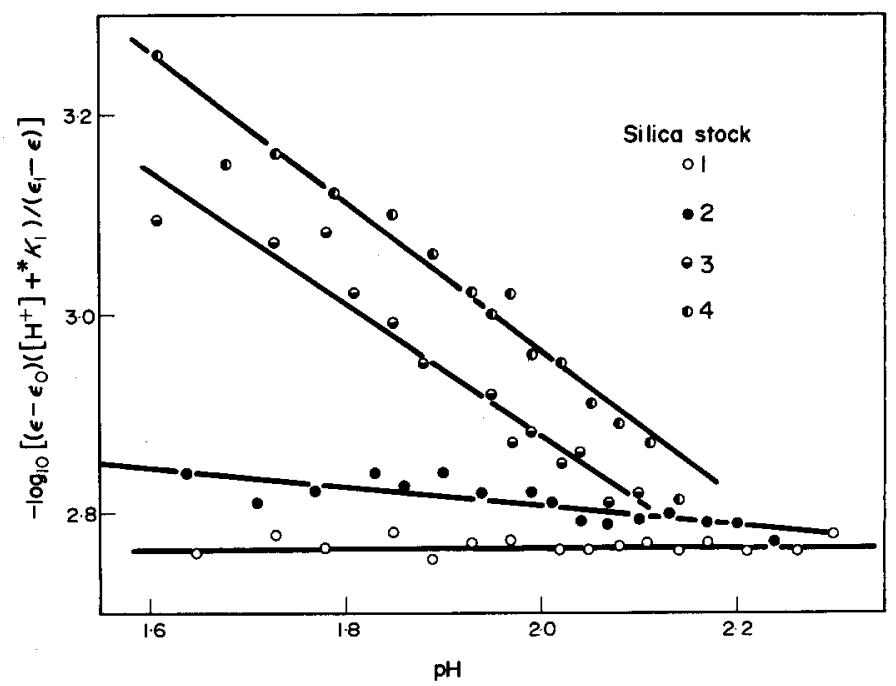

Fig. 2. Analysis of iron(III)-silica interaction according to Equation (6).

In Fig. 2 the data is plotted according to Equation (6). The value of $\epsilon_{1}$ could not be obtained from a general least squares program for each case since it is large compared to the measured values. Therefore a fixed value $\epsilon_{1}=5 \times 10^{3}$ was taken. This value was derived from the plot of solution 1 given in Fig. 1. The 
plots and the parameters derived from them are not very sensitive to the choice of $\epsilon_{1}$.

Values of $n$ and $Q_{n}$ [Si] derived from a least squares fit are given in Table 1. Also given are estimates of the weight-average molecular weight for solutions 3-5. The increase of $n$ with increasing polymerization is in the direction expected from the above discussion. The decrease of $Q_{n}$ [Si] with increasing polymerization is more difficult to interpret, involving as it does the factor $\left[\mathrm{H}^{+}\right]^{n}$. It would appear that since the values of $\epsilon$ become comparable for all solutions as the $\mathrm{pH}$ is increased above 2 , the polymeric silica is tying up an amount of iron comparable to that complexed by an equivalent amount of monomeric silicic acid. Since there are undoubtedly a smaller number of free silanol groups in polymeric silica, a compensating role must be played by the increasing acidity of these groups.

Table 1. Parameters for interaction of iron with silica in various degrees of polymerization

\begin{tabular}{cccr}
\hline Silica stock & $n$ & $-\log _{10}\left(Q_{n}[\right.$ Si $\left.]\right)$ & Mol.wt. \\
\hline 1 & 1.02 & $2 \cdot 76$ & \\
2 & $1 \cdot 10$ & 3.00 & \\
3 & 1.67 & 4.22 & 13,000 \\
4 & 1.67 & 4.26 & 26,000 \\
5 & 1.76 & 4.48 & 120,000 \\
\hline
\end{tabular}

The value $n=1 \cdot 1$ for silica stock 2 is consistent with other evidence $[11,12]$ that 1 molar sodium silicate solutions contain a range of polymeric species. The distribution of polymers is essentially frozen when the solution is neutralized in excess acid.

The value of $n$ for silica stock 1 is sufficiently close to 1 to indicate that this solution contains primarily monomeric, or at least small, species. The possibility of some dimeric, trimeric, or other multimeric species existing in this solution cannot be discounted. Evidence for their existence lies in the appreciable absorbance of silica blank solutions at $272 \mathrm{~m} \mu$. Certainly some will be formed in the mixing process, since polymerization is very rapid in the intermediate $\mathrm{pH}$ 's through which the solution must pass, however briefly. If we set $n=1.00$ in Equation 5 and perform a least squares treatment of the data for solution 1, a value $Q_{1}=0.18$ is obtained. This cannot be considered to be good agreement with the value $Q_{1}=0.57$ obtained previously. Given the uncertainty in the composition of the silica stock, it may be that better agreement cannot be expected. Settlement of this question awaits detailed analysis for the silicic acid species, perhaps by the methods of Lentz [11].

A few light scattering measurements were made to determine if ferric ion has an appreciable effect on the rate of polymerization of silica under the conditions of our experiments. The turbidity of several solutions $0 \cdot 1 \mathrm{M}$ in silicate, $0-1 \times 10^{-4}$ $\mathrm{M}$ in $\mathrm{Fe}^{3+}$, and with $\mathrm{pH} 2 \cdot 1-2 \cdot 2$ was followed for several days. No significant 
Table 2. Equilibrium constants for the interaction of silicic acid with uranyl ion

\begin{tabular}{cc}
\hline$[S i]$ & $Q_{1}$ \\
\hline 0.024 & 0.0111 \\
0.031 & 0.0110 \\
0.035 & 0.0094 \\
\hline
\end{tabular}

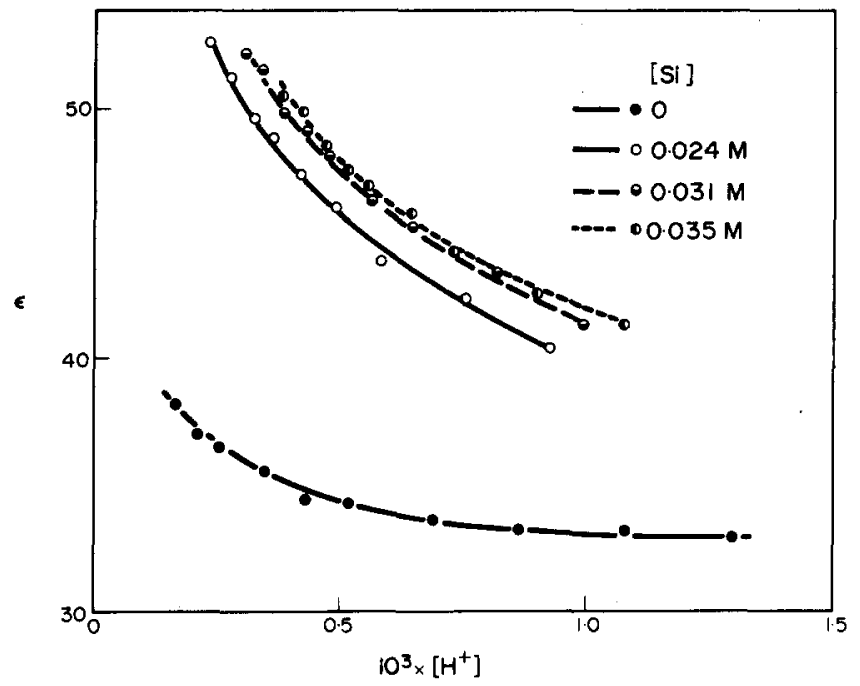

Fig. 3. Absorbance of $6.4 \times 10^{-4} \mathrm{M} \mathrm{UO}_{2}\left(\mathrm{ClO}_{4}\right)_{2}$ solutions in the presence of silicic acid

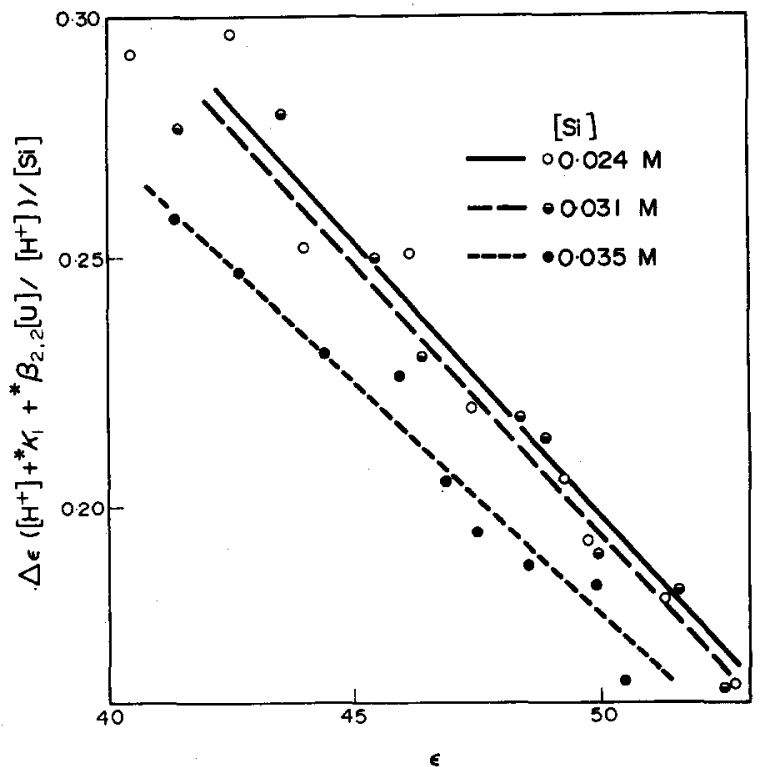

Fig. 4. Analysis of uranyl-silica interaction according to Equation (5) with $n=1$. 
differences were noted in the rate of turbidity increase. We can therefore discount the effect of iron concentration on polymerization rate as a critical effect in our experiments.

Uranium. The strong interaction of the uranyl ion with silica gel[13] and with a glass surface [14] indicated that a silicato complex might be detectable in relatively acid conditions as was the case for iron(III). The absorption peak centered at about $310 \mathrm{~m} \mu$ indeed shows an increase in absorbance and a slight shift to longer wavelengths when silicic acid is added to uranyl perchlorate solutions. Smaller effects are observed elsewhere in the visible-u.v. spectrum. The maximum difference between uranyl solutions with and without silicate occurs at about $325 \mathrm{~m} \mu$. Our measurements were therefore concentrated at this wavelength.

Figure 3 shows the dependence on $\mathrm{pH}$ and silica concentration of the molar absorptivity of $6.4 \times 10^{-4} \mathrm{M}$ uranyl perchlorate solutions at $325 \mathrm{~m} \mu$. The rise in absorptivity in the absence of silica at high $\mathrm{pH}$ is due to dimerization, although the actual extent of dimerization is small. This can be demonstrated by measuring the absorbance as a function of uranium concentration. It is necessary to use high silica concentrations to achieve an effect sufficiently large for mathematical analysis. Since the concentrations used lie well into the region in which polymerization of silica may occur, the caveats noted above for iron apply. It is not practical to go to higher $\mathrm{pH}$ to enhance the absorbance since the polymerization of uranyl ions would become a greater problem.

The absorbance data is plotted according to Equation (8) with $n=1$ in Fig. 4 . The data for a given silica concentration is obtained from a single stock solution. The constants ${ }^{*} K_{1}=2 \times 10^{-6}$ and ${ }^{*} \beta_{2,2}=1 \cdot 2 \times 10^{-6}$ were used [15]. The data for a given stock solution have good self-consistency, but there is some variation between different silica concentrations. Table 2 gives values of equilibrium constants obtained by a least squares fit for the different stock solutions. The existence of a uranyl-silicato complex is clearly demonstrated, with $\mathrm{p} Q_{1} \sim \mathbf{2 \cdot 0}$.

Acknowledgements - Special thanks are due to Mrs. Rosa Ang, who performed many of the measurements, and Dr. George Zografi of the College of Pharmacy of the University of Michigan, who made certain analytical apparatus available to us. This work was supported in part by Grant No. 106,050 DUW from the Federal Water Quality Administration, U.S. Department of the Interior.

13. J. Stanton and R. W. Maatman, J. Colloid Sci. 18, 132 (1963).

14. E. L. Mark, R. A. Porter and R. N. Chanda, J. Coll. Interf. Sci. 35, 133 (1971).

15. C. F. Baes and N. J. Meyer, Inorg. Chem. 1, 780 (1962). 